\title{
Salt Consumption Patterns and Iodine Nutrition Status of Pregnant Women in Coastal Region
}

\author{
Moh Moh Hlaing, Mya Ohnmar, Sandar Tun, Thidar Khine, Theingi Thwin \\ Nutrition Research Division, Department of Medical Research, Ministry of Health and Sports, \\ Yangon, Republic of the Union of Myanmar \\ Email: mmmhlaing73@gmail.com, mohmohhlaing@mohs.gov.mm
}

How to cite this paper: Hlaing, M.M. Ohnmar, M., Tun, S., Khine, T. and Thwin, T. (2021) Salt Consumption Patterns and Iodine Nutrition Status of Pregnant Women in Coastal Region. Food and Nutrition Sciences, 12, 28-36.

https://doi.org/10.4236/fns.2021.121003

Received: November 17, 2020

Accepted: January 16, 2021

Published: January 19, 2021

Copyright $\odot 2021$ by author(s) and Scientific Research Publishing Inc. This work is licensed under the Creative Commons Attribution International License (CC BY 4.0).

http://creativecommons.org/licenses/by/4.0/

\begin{abstract}
Background: Maternal Iodine Deficiency Disorder can result in inevitable cretinism as well as miscarriages, stillbirth and low birth-weight babies. Objective: There is a need to find out contributing factors towards urinary iodine concentrations of pregnant women. Methods: Therefore, the cross-sectional, descriptive study was conducted to assess the patterns of salt utilization and iodine status of pregnant women living in coastal areas of Mon State in January and May, 2013. Result: A total of 144 pregnant women from Pa-Nga village and Kalokepi village in Thanbyuzayat township were asked by using structured questionnaires including age, parity, socioeconomic status and patterns of salt and iodine-rich foods (seaweed, fish, prawn) consumption. Casual urine samples were collected from each pregnant woman and urinary iodine concentrations were measured. Three samples each of the iodized salt and non-iodized salt from local markets were collected for determination of iodine content by the iodometric titration method. Only $83.3 \%$ of the study population consumed iodized salt and the remaining (16.7\%) consumed non-iodized salt. The median urinary iodine concentration of the study population was $105 \mu \mathrm{g} / \mathrm{L}$. The mean urinary iodine level of pregnant women who consumed iodized salt and that of pregnant women who consumed non-iodizes salt were $110.47 \pm 67.34 \mu \mathrm{g} / \mathrm{L}$ and $95.83 \pm 70.13 \mu \mathrm{g} / \mathrm{L}(\mathrm{P}=0.336)$. Iodine content of the iodized salt and non-iodized salt was $20.6 \pm 9.2 \mathrm{ppm}$ and $5.1 \pm 1.2 \mathrm{ppm}$ respectively. In conclusion, the median iodine level of pregnant women was lower than that of the optimal iodine nutrition for pregnant women, i.e., $150-250 \mu \mathrm{g} / \mathrm{L}$ and the mean iodine content of salt samples was lower than the permissible level of iodine in iodized salt, i.e., 30 $40 \mathrm{ppm}$. Conclusion: Our findings indicate that iodine nutritional status of pregnant women in this area is insufficient and salt iodization needs to be monitored for the optimal iodine content in iodized salt.
\end{abstract}




\section{Keywords}

Salt Consumption, Iodine Nutrition, Pregnant Women

\section{Introduction}

Iodine deficiency disorders are a wide spectrum of the effects of iodine deficiency on growth and development starting from the foetal stage and including brain development.

Maternal Iodine Deficiency Disorder can result in inevitable cretinism as well as miscarriages, stillbirth and low birth-weight babies. Iodine requirements sharply increase during pregnancy because of the transfer of iodine and thyroid hormone to the fetus and an increase in maternal needs for thyroid hormone, and a likely increase in maternal renal iodine clearance [1]. Thus, recommended iodine intakes during pregnancy are $250 \mu \mathrm{g} /$ day compared with $150 \mu \mathrm{g} /$ day for non-pregnant women. The corresponding median urinary iodine concentration (UIC) that indicates optimal iodine nutrition increases from $100-199 \mu \mathrm{g} / \mathrm{L}$ to $150-250 \mu \mathrm{g} / \mathrm{L}$ during pregnancy [2].

In Myanmar, for IDD elimination, the salt legislation and implementation of universal salt iodization have been launched since 1997. Due to regular supplies of iodised salt, visible goitre rate among children (6 - 11 years) has dropped from $33 \%$ (1994) to 5.5\% (2004). However, school-based surveys conducted in March 2008 showed that there were certain pockets areas (Mon and Rakhine State) where $81 \%$ and $72 \%$ of households have been consuming iodized salt [3]. Although, pregnancy is a critical time for iodine needs, iodized salt consumption patterns of pregnant women living in the coastal regions may be variable because non-iodized salt, produced by unregistered small-scale factories including solar salt production, could be available.

Measurements of urinary iodine levels in school-aged children are often used for assessment of iodine deficiency disorder in populations because of the vulnerability of children to iodine deficiency and access in school-based survey. Adequate nature of iodine nutrition in school-aged school cannot be assumed that iodine status of pregnant women is optimal. Therefore, contributing factors towards urinary iodine concentrations of pregnant women need to be measured as an indicator for iodine nutrition status of really risk population.

\section{Objectives}

- To determine urinary iodine concentration of casual urine samples of pregnant women as an indicator of iodine nutrition status.

- To measure the iodine content of salt consumed by the pregnant women in coastal area.

- To identify the consumption patterns of salts, fish sauce and iodine rich foods among pregnant women living in coastal area. 
- To identify contributing factors towards urinary iodine levels of pregnant women living in coastal area.

\section{Materials and Method}

\section{Study design}

The study design was a cross-sectional, descriptive study.

\section{Sample size calculation}

Using the data on effective iodizes salt consumption was 48.23\% [4], with absolute precision $8 \%$ and $95 \%$ Confidence Interval, the sample size was 150 pregnant women using the following formula, $n=z_{(1-\alpha / 2)}^{2} p q / d^{2}$.

\section{Study population and study area}

All eligible 144 pregnant women were recruited from selected villages (Pa-nga village and Kalokepi village) at $\mathrm{n}$ Thanbyuzayat township in Mon State.

\section{Study Period}

From January 2013 to August 2013.

\section{Sampling}

Among coastal areas of Myanmar, Mon State was purposely chosen due to logistic reasons. Two study sites (villages) in the coastal area of Mon State was randomly chosen; one for a village with the presence of solar salt production (Pa-nga village) and the other with the absence of it (Kalokepi village). Inclusion criteria were-the pregnant women in good general health without thyroid disorders, other chronic illness, or medications, and those with no history of iodine supplements use.

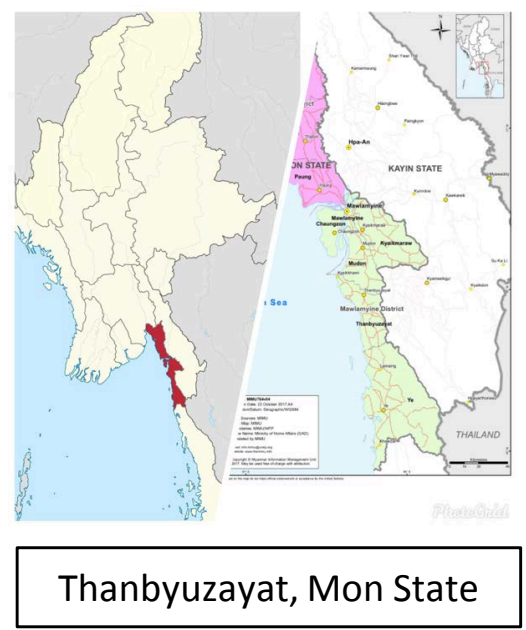

\section{Data collection}

In pilot survey, free listing was undertaken to explore the names of locally available sea foods (such as salt, fish, prawn, crab, squid, calm/mussel, octopus etc. on randomly selected ten pregnant women. Without prompting, they were asked to write down. And then pile sorting was conducted to identify commonly consumed foods s among them. Based on these findings, food frequency questionnaires for consumption pattern of iodine rich foods were constructed. 
After taking informed consents, the women will be interviewed to complete the structured questionnaires that include background characteristics, parity and salt consumption patterns (types of used salt in cooking and in fish sauce/paste or dried fish/prawn making, places of salt accessibility and frequency of iodine rich food consumption).

Measurement of urinary iodine

A casual urine sample from each woman was collected in a acid-washed $20 \mathrm{ml}$ plastic bottles containing $2 \mathrm{ml} 4 \mathrm{~N}$ hydrochloric acid. The urine samples were kept and transported on ice to the Laboratory of Nutrition Research Division. The urinary iodine concentration was measured using the method A using Ammonium Persulfate, the Sandell-Kolthoff reaction, as recommended by the International Council for Control of Iodine Deficiency Disorder (ICCIDD) [5]. Three samples each of the iodized salt and non-iodized salt from local markets were collected for determination of iodine content by the iodometric titration method [6].

\section{Data entry and analysis}

Data entry and analysis was carried out by using SPSS 11.5 for Windows. Urinary iodine level of pregnant women was presented as median values. The comparison of mean urinary iodine was calculated by student $\mathrm{t}$-test and relation between urinary iodine level and associated factors were calculated with $\mathrm{X}^{2}$ test. $\mathrm{P}$-values $<0.05$ is considered as a statistical significance.

\section{Ethical considerations}

The proposal was submitted to the Institutional Ethical Review Committee, Department of Medical Research (Lower Myanmar) for approval.

\section{Findings}

A total of 144 pregnant women were recruited in this study. Among 144 pregnant women, 88 were from Pa-nga village and 56 were from Kalokepi village. The mean age of pregnant women was $29.92 \pm 6.58$ years ranging from 16 to 46 years. Most of the pregnant women were in $2^{\text {nd }}$ trimester.

In Table 1, about $50 \%$ and $60 \%$ of pregnant women were between $30-39$ year old and at the $2^{\text {nd }}$ trimester of pregnancy respectively.

\section{Salt consumption pattern}

Only $83.3 \%$ of the study population consumed iodized salt and the remaining (16.7\%) consumed non-iodized salt. Among 144 pregnant women, 28 pregnant women used solar salt for making dried fish for household.

Figure 1 shows that, $16.7 \%$ of pregnant women in this area consumed solar salt.

Table 2 shows that $25.7 \%$ of pregnant women consumed seaweed (wet or dried) and only $2.1 \%$ of pregnant women did not eat marine fish. High percentage of pregnant women consumed marine fish, prawn, crab, squid and calm/mussel 1 - 3 day.

In Table 3, mean Iodine content of the iodized salt and non-iodized salt were $20.6 \pm 9.2 \mathrm{ppm}$ and $5.1 \pm 1.2 \mathrm{ppm}$, respectively. 


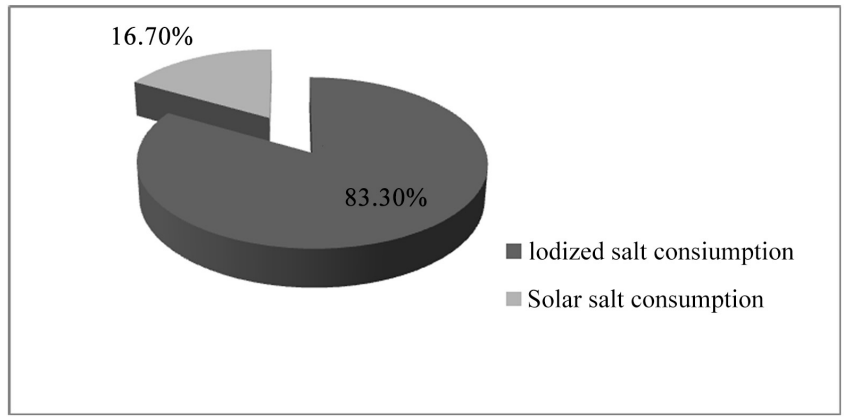

Figure 1. Salt consumption of pregnant women.

Table 1. Background characteristic of pregnant women.

\begin{tabular}{lll}
\hline & Frequency & Percent \\
\hline Age group & & \\
$\bullet<20$ years & 11 & 7.6 \\
$\bullet 20$ - 29 years & 55 & 38.2 \\
$\bullet 30$ - 39 years & 68 & 47.2 \\
$\bullet \geq 40$ years & 10 & 6.9 \\
Trimester & & \\
$\bullet 1^{\text {st }}$ trimester & 19 & 13.2 \\
$\bullet 2^{\text {nd }}$ trimester & 83 & 57.6 \\
$\bullet 3^{\text {rd }}$ trimester & 42 & 29.2 \\
\hline
\end{tabular}

Table 2. Dietary intake iodine rich food s of pregnant women.

\begin{tabular}{cccccc}
\hline & $\begin{array}{c}\text { No } \\
\text { consumption }\end{array}$ & $\begin{array}{c}1-3 \text { days } \\
\text { Per month }\end{array}$ & $\begin{array}{c}1-3 \text { days } \\
\text { Per week }\end{array}$ & $\begin{array}{r}4-6 \text { days } \\
\text { Per week }\end{array}$ & Daily \\
\hline Sea weed & $107(74.3 \%)$ & $16(11.1 \%)$ & $18(12.5 \%)$ & $1(0.7 \%)$ & $2(1.4 \%)$ \\
Sea water fish & $3(2.1 \%)$ & $7(4.9 \%)$ & $70(48.6 \%)$ & $12(8.3 \%)$ & $52(36.1 \%)$ \\
Prawn & $36(25.0 \%)$ & $22(15.3 \%)$ & $73(50.7 \%)$ & $4(2.8 \%)$ & $9(6.3 \%)$ \\
Crab & $52(36.1 \%)$ & $40(27.8 \%)$ & $51(35.4 \%)$ & - & $1(0.7 \%)$ \\
Squid & $62(43.1 \%)$ & $40(27.8 \%)$ & $39(27.1 \%)$ & $2(1.4 \%)$ & $1(0.7 \%)$ \\
Clam/Mussel & $131(91.0 \%)$ & $6(4.2 \%)$ & $7(4.9 \%)$ & - & - \\
Fish sauce & $49(34.0 \%)$ & $31(21.6 \%)$ & $54(37.5 \%)$ & $4(2.8 \%)$ & $6(4.2 \%)$ \\
Fish paste & $24(16.7 \%)$ & $25(17.4 \%)$ & $62(43.1 \%)$ & $(1.4 \%)$ & $31(21.5 \%)$ \\
Dried fish & $18(12.5 \%)$ & $40(27.8 \%)$ & $76(52.8 \%)$ & $5(3.5 \%)$ & $5(3.5 \%)$ \\
\hline
\end{tabular}

Table 3. Iodine content of salt samples.

\begin{tabular}{ccc}
\hline & Iodized salt & Non iodized salt \\
\hline Sample 1 & $20.7 \pm 2.19$ & $5.85 \pm 0.78$ \\
Sample 2 & $29.7 \pm 2.9$ & $5.85 \pm 0.78$ \\
Sample 3 & $11.4 \pm 1.13$ & $3.7 \pm 0.70$ \\
Mean & 20.85 & 5.13 \\
SD & 9.15 & 1.24 \\
\hline
\end{tabular}




\section{Urinary iodine concentration of pregnant women}

The median urinary iodine concentration of the study population was 105 $\mu \mathrm{g} / \mathrm{L}$ ranging from $5 \mu \mathrm{g} / \mathrm{L}$ to $295 \mu \mathrm{g} / \mathrm{L}$. The mean urinary iodine level of pregnant women who consumed iodized salt and that of pregnant women who consumed non-iodized salt were $110.47 \pm 67.34 \mu \mathrm{g} / \mathrm{L}$ and $95.83 \pm 70.13 \mu \mathrm{g} / \mathrm{L}(\mathrm{P}=0.336)$.

Figure 2 illustrates that, only 38 (26.4\%) pregnant women had optimal urinary iodine level that is $>150 \mu \mathrm{g} / \mathrm{L}$. Nearly half of pregnant women $(45.1 \%)$ had urinary iodine level $<100 \mu \mathrm{g} / \mathrm{L}$.

According to Table 4, percentage of pregnant women with urinary iodine concentration $<150 \mu \mathrm{g} / \mathrm{L}$ were not much differ among gestation of pregnant women.

In Table 5, the mean urinary iodine level of pregnant women who consumed iodized salt and that of pregnant women who consumed non-iodizes salt were $110.47 \pm 67.34 \mu \mathrm{g} / \mathrm{L}$ and $95.83 \pm 70.13 \mu \mathrm{g} / \mathrm{L}(\mathrm{P}=0.336)$. Pregnant women with urinary iodine concentration $<150 \mu \mathrm{g} / \mathrm{L}$ was a little bit higher in women who used solar salt for consumption.

In Table 6, 3 pregnant women did not consume sea water fish and their Urinary iodine concentration was less than $150 \mu \mathrm{g} / \mathrm{L}$.

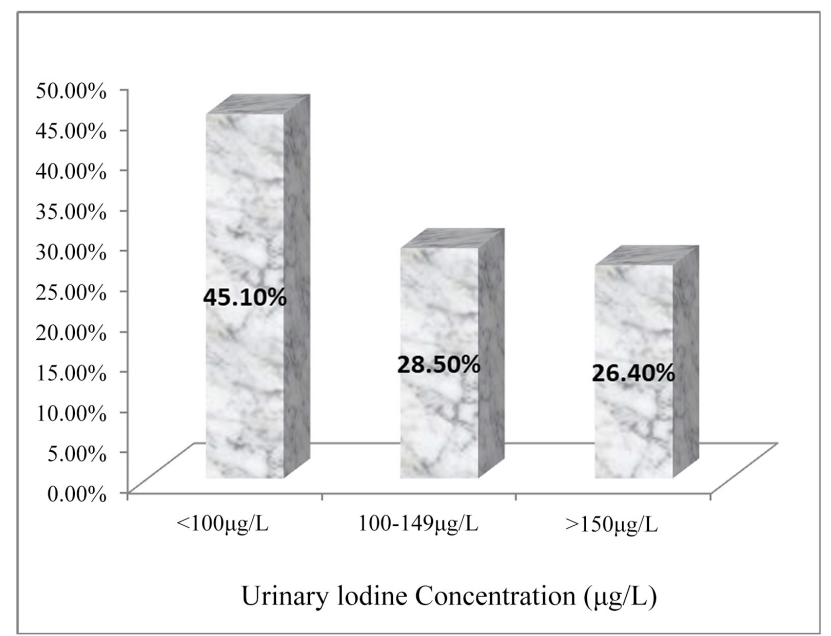

Figure 2. Urinary iodine concentration of pregnant women.

Table 4. Urinary iodine concentration of pregnant women according to trimester and distribution of concentrations.

\begin{tabular}{cccccc}
\hline \multirow{2}{*}{ Trimester } & Number & \multicolumn{2}{c}{$\begin{array}{c}\text { Urinary iodine } \\
\text { concentration }(\mu \mathrm{g} / \mathrm{L})\end{array}$} & \multicolumn{2}{c}{$\begin{array}{c}\text { Urinary iodine } \\
\text { concentration distribution }\end{array}$} \\
\cline { 3 - 6 } & & Median & Range & $<150 \mu \mathrm{g} / \mathrm{L}$ & $\geq 150 \mu \mathrm{g} / \mathrm{L}$ \\
\hline $1^{\text {st }}$ & 19 & 110 & $5-255$ & $13(68.4 \%)$ & $6(31.6 \%)$ \\
$2^{\text {nd }}$ & 83 & 105 & $5-245$ & $61(73.5 \%)$ & $22(26.5 \%)$ \\
$3^{\text {rd }}$ & 42 & 90 & $5-295$ & $32(76.2 \%)$ & $10(23.8 \%)$ \\
& & & & \multicolumn{2}{c}{ P-value $=0.4$} \\
\hline
\end{tabular}


Table 5. Urinary iodine concentration of pregnant women according to type of salt used for consumption and distribution of concentrations.

\begin{tabular}{cccccc}
\hline \multirow{2}{*}{$\begin{array}{c}\text { Type of salt used } \\
\text { for consumption }\end{array}$} & Number & \multicolumn{2}{c}{$\begin{array}{c}\text { Urinary iodine } \\
\text { concentration }(\mu \mathrm{g} / \mathrm{L})\end{array}$} & \multicolumn{2}{c}{$\begin{array}{c}\text { Urinary iodine } \\
\text { concentration distribution }\end{array}$} \\
\cline { 2 - 6 } & & Median & Range & $<150 \mu \mathrm{g} / \mathrm{L}$ & $\geq 150 \mu \mathrm{g} / \mathrm{L}$ \\
\hline Solar salt & 24 & 102.5 & $10-235$ & $20(83.3 \%)$ & $4(16.7 \%)$ \\
Iodized salt & 120 & 105.5 & $5-295$ & $86(71.7 \%)$ & $34(28.3 \%)$ \\
& & & & \multicolumn{2}{c}{ P- value $=0.3$} \\
\hline
\end{tabular}

Table 6. Urinary iodine level of pregnant women according to consumption pattern of sea foods and salt containing foods.

\begin{tabular}{ccccc}
\hline \multirow{2}{*}{ Consumption of } & & $\begin{array}{c}\text { Urinary iodine level } \\
<150 \mu \mathrm{g} / \mathrm{L}\end{array}$ & $\begin{array}{c}\text { Urinary iodine level } \\
\geq 150 \mu \mathrm{g} / \mathrm{L}\end{array}$ & Total \\
\hline \multirow{2}{*}{ Sea water fish } & No & $3(100 \%)$ & 0 & 3 \\
& Yes & $107(73 \%)$ & $38(27 \%)$ & 141 \\
Prawn & No & $25(69.4 \%)$ & $11(30.6 \%)$ & 36 \\
& Yes & $103(95.4 \%)$ & $5(4.6 \%)$ & 108 \\
Crab & No & $37(71.2 \%)$ & $15(28.8 \%)$ & 52 \\
& Yes & $69(75.0 \%)$ & $23(25.0 \%)$ & 92 \\
Squid & No & $44(70.9 \%)$ & $18(29.1 \%)$ & 62 \\
& Yes & $62(75.6 \%)$ & $20(24.4 \%)$ & 82 \\
Calm/Mussel & No & $95(72.5 \%)$ & $36(27.5 \%)$ & 131 \\
& Yes & $11(84.6 \%)$ & $2(15.4 \%)$ & 13 \\
Fish sauce & No & $34(69.4 \%)$ & $15(30.6 \%)$ & 49 \\
& Yes & $72(75.8 \%)$ & $23(24.2 \%)$ & 95 \\
Fish paste & No & $19(79.2 \%)$ & $5(20.8 \%)$ & 24 \\
& Yes & $87(72.5 \%)$ & $33(27.5 \%)$ & 120 \\
& No & $16(88.9 \%)$ & $2(11.1 \%)$ & 18 \\
& $90(71.4 \%)$ & $36(28.6 \%)$ & 126 \\
\hline
\end{tabular}

\section{Discussion}

In this study $16.7 \%$ of study population used solar salt for consumption. And 28 (19.4\%) pregnant women used solar salt for making dried fish for household consumption. This may be due to the study villages are located in costal area of Mon states and solar salt are easily available from salt factories and local market.

The median urinary iodine concentration was $105 \mu \mathrm{g} / \mathrm{L}$ that was lower than the recommended minimum adequate urinary iodine concentration (UIC) of $150-250 \mu \mathrm{g} / \mathrm{L}$. Among 144 pregnant women, $73.6 \%$ of pregnant women had urinary iodine level less than $150 \mu \mathrm{g} / \mathrm{L}$. Data from National Nutrition Centre, Department of Health, Myanmar showed that median urinary iodine excretion among pregnant was $205 \mu \mathrm{g} / \mathrm{L}$ (2004) and percentage of with median urinary 
excretion below $100 \mu \mathrm{g} / \mathrm{L}$ was $22.3 \%$ [7]. In this study median urinary excretion below $100 \mu \mathrm{g} / \mathrm{L}$ was $45.1 \%$. The median urinary iodine concentration from this study is similar with the median urinary iodine concentration of Thai pregnant women that is $108 \mu \mathrm{g} / \mathrm{L}(11-558 \mu \mathrm{g} / \mathrm{L})$ in 2009 [8]. In this study, the median urinary concentration of pregnant women in $1^{\text {st }}, 2^{\text {nd }}$ and $3^{\text {rd }}$ trimesters was 110 $\mu \mathrm{g} / \mathrm{L}, 105 \mu \mathrm{g} / \mathrm{L}$ and $90 \mu \mathrm{g} / \mathrm{L}$ respectively. There is no difference in median urinary iodine concentration between trimesters $(P=0.4)$. These finding is consistent with results of Thai pregnant women.

The mean urinary iodine level did not differ between pregnant women who consumed iodized salt and those consumed non-iodizes salt $(P=0.336)$. All of the pregnant women consumed salt daily. There is no relationship between sea products and urinary iodine level. The most likely explanation may be the lower iodine contents of foods consumed by pregnant women. Our study also found that the iodine content of salt samples were lower than the permissible level of iodine in iodized salt, i.e., $30-40 \mathrm{ppm}$ even in iodized salt. This may be another explanation of low urinary iodine level. In our study, we could not analyze the iodine contents of foods consumed by pregnant women in this area. However, iodine contents of marine and sea water fish, other sea products were measured in 1996 [9]. In this study, iodine contents of fresh water fish, sea water fish and prawn were 4.3 to $33.6 \mu \mathrm{g} / 100 \mathrm{~g}, 10.4$ to $122.96 \mu \mathrm{g} / 100 \mathrm{~g}$ and 78.14 to 282.48 $\mu \mathrm{g} / 100 \mathrm{~g}$ respectively. Mean iodine content of squid and crab were $21.68 \pm 3.09$ $\mu \mathrm{g} / 100 \mathrm{~g}$ and $14.24 \pm 2.57 \mu \mathrm{g} / 100 \mathrm{~g}$. Iodine content of dried sea fish was 39.43 to $541.54 \mu \mathrm{g} / 100 \mathrm{~g}$. There were high iodine contents in fermented fish paste from Rakhine (558. $\pm 13.08 \mu \mathrm{g} / 100 \mathrm{~g})$, Myeik (415.0 $\pm 11.51 \mu \mathrm{g} / 100 \mathrm{~g})$, Pathein (399.0 \pm $10.02 \mu \mathrm{g} / 100 \mathrm{~g})$. However, iodine contents of sea foods from Mon state did not analyzed in this study. Therefore, iodine contents of these foods cannot represent the iodine contents of food in Mon state. The iodine content in plants and animal is determined by the environment in which they grow. According to Lunde et al. (1930), the fishing locality had a considerable influence. These differences might depend upon the lower iodine of the plankton. Soil erosion can cause low iodine contents in the soil as well in foods.

In Myanmar, source of iodine from foods were only from iodized salt and sea foods. Universal salt iodization is only one food fortification programme in Myanmar. In Thailand, Salt, Fish Sauce, Soy Sauce and Cooking Brine are fortified with iodine. Edible salt and salt for food processing must have iodine content between 20 - 40 parts per million, whereas fish sauce, soy sauce and cooking brine must have iodine content between 2 - 3 parts per million.

\section{Conclusion and Recommendations}

In conclusion, the median UIC indicated that iodine deficiency in pregnant women in coastal area of Mon state. Therefore, there is needed to improve the current status of salt iodization programme and continue monitoring of iodine content in salt at factories, retail shop and household levels. Monitoring of the urinary iodine concentration among vulnerable groups such as children, preg- 
nant women and lactation mothers should be done. Nationwide surveillance of the iodine nutritional status of these vulnerable groups should be done.

\section{Limitation of the Study}

This study was conducted only in one township in Mon State therefore the urinary iodine level of this study cannot represent the pregnant women living in Coastal area of Myanmar. It would have been useful to include nonpregnant as control group to help ascertain whether lower UI concentrations during pregnancy could be attributed to pregnancy itself or to dietary intake of this population.

\section{Acknowledgements}

We gratefully acknowledged the D Dr. Pone Nya, Township Medical officer, township health nurse and midwives from Tanbyuzayat Township. We mention our heartfelt thanks to the pregnant women from Pa-Nga village and Kalokepi village in Tanbyuzayat Township. The financial support of the World Health Organization is also gratefully acknowledged. My sincere gratitude also goes to Research team of Nutrition Research Division, Department of the Research.

\section{Conflicts of Interest}

The authors declare no conflicts of interest regarding the publication of this paper.

\section{References}

[1] Zimmermann, M.B., Jooste, P.L. and Pandav, C. (2008) Iodine Deficiency Disorders. Lancet, 372, 1251-1262. https://doi.org/10.1016/S0140-6736(08)61005-3

[2] WHO, ICCIDD, UNICEF (2007) Assessment of the Iodine Deficiency Disorders and Monitoring Their Elimination. 3rd Edition.

[3] UNICEF (2008) A Review of the Status of Salt Production and Salt Iodisation in the Union of Myanmar.

[4] Ministry of Health, Myanmar (2011) Health in Myanmar 2011.

[5] Dunn, J.T. (1993) Methods for Measuring Iodine in Urine. International Council for Control of Iodine Deficiency Disorder, 18-23.

[6] Hetzel, B.S., Dunn, J.T., Stanbury, J.B., et al. (1987) The Prevention and Control of Iodine Deficiency Disorders. Elsevier, Amsterdam.

[7] National Nutrition Centre, Department of Health, Ministry of Health Sports, Union Republic of Myanmar (2004) Unpublished Report.

[8] Gowachirapant, S., Winichagoon, P., Wyss, L., Tong, B., Baumgartner, J., MelseBoonstra A. and Zimmermann, M.B. (2009) Urinary Iodine Concentrations Indicate Iodine Deficiency in Pregnant Thai Women but Iodine Sufficiency in Their School-Aged Children. The Journal of Nutrition, 139, 1169-1172. https://doi.org/10.3945/jn.108.100438

[9] Thiri, M.O. (1996) Comparison of Iodine Content in Fresh and Sea Water Fish and Crustaceans. Thesis, University of Yangon, Yangon. 